\title{
ANÁLISE DO PERFIL PROFISSIONAL DOS EGRESSOS DO CURSO DE FISIOTERAPIA DA UNIVERSIDADE REGIONAL DE BLUMENAU
}

\section{ANALYSIS OF THE PROFESSIONAL PROFILE OF STUDENTS FROM THE COURSE OF PHYSIOTHERAPY OF THE UNIVERSIDADE REGIONAL DE BLUMENAU}

Débora Ewelyn Scheidt (ORCID: 0000-0002-8554-2954)

Amanda Paola Goetzinger ${ }^{1}$

Julia Silveira Ramos Keske ${ }^{1}$

José Francisco Gontan Albiero (ORCID: 0000-0002-9042-395X) ${ }^{1}$

Autor Correspondente

Débora Ewelyn Scheidt

E-mail: deborascheidt13@gmail.com

${ }^{1}$ Curso de Fisioterapia, Fundação Universidade Regional de Blumenau.

a) Trabalho acadêmico resultante do trabalho de conclusão de curso de Amanda Paola Goetzinger e Julia Silveira Ramos Keske "Análise do Perfil Profissional dos Egressos do Curso de Fisioterapia da Universidade Regional de Blumenau / SC de 2007 a 2016", defendido em 2017 na Fundação Universidade Regional de Blumenau.

\begin{abstract}
RESUMO
Objetivos: investigar a situação atual e as perspectivas da atuação fisioterapêutica dos egressos formados em Fisioterapia pela Fundação Universidade Regional de Blumenau (Furb); confrontar os dados com pesquisa semelhante realizada há dez anos; conhecer a percepção dos egressos sobre sua formação correlacionando com sua trajetória profissional. Métodos: pesquisa quantitativa de caráter exploratório com amostragem por conveniência de 181 egressos formados na Furb entre os anos de 2007 e 2016. Foi aplicado questionário on-line composto por 15 questões fechadas e de múltipla escolha com itens referentes a suas atividades profissionais divididas em quatro categorias: I) quanto à formação; II) quanto ao primeiro emprego; III) quanto à situação atual; IV) quanto à especialização profissional. Resultados: a maior parte dos participantes considerou sua formação sólida, capaz de conceder segurança na vida profissional. Destacam a estrutura da universidade e as experiências de estágio como pontos fortes. Evidenciam rapidez para entrada no mercado de trabalho e satisfeitos com sua situação profissional. Mostraram-se comprometidos com sua permanente qualificação por meio de cursos e pós-graduações. Conclusão: a avaliação da graduação utilizando a percepção dos egressos mostra-se um importante e viável elemento para aprimorar a formação de futuros profissionais de maneira constante.
\end{abstract}

Palavras-chave: Área de atuação profissional; Avaliação institucional; Fisioterapia.

\begin{abstract}
Objective: investigate the current situation and the perspectives of the physiotherapeutic performance of the graduates from the Universidade Regional de Blumenau (Furb) in physiotherapy. Confront the data with a similar research performed ten years ago. Know the perception of the graduates about their training correlating with their professional career. Methodology: quantitative research with exploratory character with convenience sampling of 181 graduates from the FURB between the years 2007 and 2016. An online questionnaire was applied composed of 15 multiple choice closed questions with items related to their professional activities divided into four categories: I) About the training; II) About the first job; III) About the current situation; IV) About the professional qualification. Results: most participants considered their training solid, capable of providing security in professional life. They highlight the structure of the university and the internship experience as strengths. They highlight fastness in entering the job market and satisfaction with their professional situation. They appeared to be compromised with their permanent qualification through courses and post graduations. Conclusion: the evaluation of graduated students using their perception is an important and viable element to constantly improve the training of future professionals.
\end{abstract}

Keywords: Professional practice location; Institutional evaluation; Physical therapy. 


\section{INTRODUÇÃO}

Neste ano, a Fisioterapia no Brasil completa 50 anos de reconhecimento. Nesse período, a profissão passou por vários processos de transformação. $\mathrm{A}$ Fisioterapia evoluiu de uma profissão da saúde que nasceu da intenção de auxiliar o médico, com atuação limitada à reabilitação motora, para uma profissão autônoma, com inserção nas diversas áreas clínicas e com espaços ampliados na prevenção e promoção da saúde ${ }^{1}$.

Em Santa Catarina, a Fundação Universidade Regional de Blumenau (Furb) foi a segunda escola de formação de fisioterapeutas, iniciando sua primeira turma em 1994. Desde seu início, pautou-se em uma formação generalista, científica e comprometida com a sociedade. Nesses 27 anos, formou mais de 900 fisioterapeutas que seguiram por múltiplas áreas de atuação. Ao longo desse período, o curso buscou avaliação permanente de seus processos e foi qualificando seu Projeto Político-Pedagógico sistematicamente à luz das Diretrizes Curriculares Nacionais e das determinações dos conselhos da profissão.

Uma boa avaliação fornece informação sobre o que se está fazendo, se os objetivos estão sendo alcançados e se apontam novas estratégias. Constitui-se de um processo contínuo, que encoraja a reflexão sobre resultados e dá base para estratégias futuras ${ }^{2}$.

A avaliação é a ferramenta principal para organização e implementação das reformas educacionais ${ }^{3}$. Os processos de avaliação no ensino superior são políticas públicas com grande capacidade para promover mudanças e adequações nos sistemas de ensino ante as demandas sociais ${ }^{4}$.

Uma vez que as universidades são a fonte de profissionais diplomados aptos para o exercício profissional na sociedade, é necessário que essas obtenham informações no que se refere aos seus egressos para que recebam um feedback quanto à efetiva contribuição da sua organização para com a sociedade. A não obtenção de informações relativas ao ensino ofertado pela universidade, por parte dos seus egressos, acaba por não possibilitar as mudanças necessárias nos currículos e processos ensino-aprendizagem das Instituições de Ensino Superior (IES) $)^{5}$.

Nesse sentido, esta pesquisa objetivou conhecer a percepção dos egressos do curso (2006 - 2017) sobre: a) pontos fortes e fragilidades do ensino da graduação na percepção dos egressos do curso; b) satisfação do egresso do Curso de Fisioterapia com a sua formação e a profissão; c) trajetória profissional, área de atuação, especialização e características de seu trabalho.

Com a pesquisa e seus dados, tem-se a expectativa que subsidiem os processos avaliativos, as discussões e as tomadas de decisões do Núcleo Docente Estruturante sobre as adequações do novo Projeto Pedagógico de Curso (PPC).

\section{MÉTODOS}

Esta pesquisa consiste em um estudo quantitativo exploratório. As pesquisas de levantamento de dados caracterizam-se pela interrogação das pessoas cujo comportamento se deseja conhecer. Já a pesquisa exploratória tem como objetivo proporcionar maior familiaridade com o problema, visando torná-lo mais explícito ou a constituir hipóteses ${ }^{6}$.

A pesquisa foi realizada com egressos do Curso de Fisioterapia da Furb, que está localizada na cidade de Blumenau e que se constitui em uma das principais universidades da região do Vale do Itajaí.

A população constou de todos 
os egressos do Curso de Fisioterapia da Furb formados entre 2007/01 e 2016/1 (nove anos), perfazendo um total de 344 indivíduos segundo a listagem oficial da Sessão Diplomas da Furb. A amostra do tipo conveniência foi composta por 181 egressos, o que correspondeu a 52,60\% do número total de formados que retornaram os questionários devidamente respondidos no tempo determinado.

Como critério de inclusão na pesquisa, foi necessário o encaminhamento do questionário completo no período previsto. Já como critério de exclusão, foram considerados: a) participantes em desacordo com o Termo de Consentimento Livre e Esclarecido (TCLE) anexado ao questionário na plataforma de criação e edição on-line de documentos Google Docs; b) egressos formados anteriormente a 2007/1 e que participaram do outro estudo; c) profissionais que nunca atuaram na área de fisioterapia.

Como instrumento de pesquisa para o levantamento de dados, foi utilizado um questionário adaptado de Struck e Bretzke contendo 15 perguntas fechadas de múltipla escolha divididas em 4 categorias, sendo elas: I) quanto à formação; II) quanto ao primeiro emprego; III) quanto à situação atual do egresso; e IV) quanto à sua especialização profissional ${ }^{7}$.

A pesquisa foi aprovada pelo Comitê de Ética em Pesquisa em Seres Humanos da Furb, sob o parecer 2.146.994.

Com tal aprovação, o passo seguinte foi buscar na Sessão Diplomas da Furb os endereços eletrônicos dos egressos para o envio do questionário pela plataforma de criação e edição on-line de documentos - Google Docs, via e-mail.

Juntamente, foi enviada, também, uma breve apresentação sobre a pesquisa, com o link do Questionário Google Docs a ser respondido, que possuía o TCLE anexado. Inicialmente, ao acessar o Questionário do Google Docs, o participante deveria concordar com o TCLE para ter acesso e responder às perguntas seguintes da pesquisa.

Para a coleta de dados, o e-mail contendo o questionário e as informações foi enviado em três tentativas, em um intervalo de 10 dias entre o encaminhamento de cada um. No primeiro período, obtiveram-se então 101 questionários respondidos devidamente, seguido de 51 na segunda etapa e de 29 na última tentativa, totalizando 181 respostas de egressos (ou seja, $52,60 \%$ do número total de sujeitos).

Os dados obtidos com a presente pesquisa foram analisados quantitativamente. Por meio da estatística descritiva, os resultados foram analisados e apresentados em forma de tabelas e discussões em cada categoria.

\section{RESULTADOS}

A apresentação dos resultados foi dividida por categorias conforme o questionário aplicado, sendo elas: I) quanto à formação; II) quanto ao primeiro emprego; III) quanto à situação atual do egresso e IV) quanto à sua especialização profissional.

Como já descrito anteriormente, a amostra foi composta por 181 egressos do Curso de Fisioterapia da Furb formados entre os anos de 2007 e 2016, apresentando uma variedade no tempo de profissão entre um e dez anos.

Quanto ao sexo dos participantes da pesquisa, foi constatada uma maior quantidade de egressos do sexo feminino, $87,85 \%$ dos participantes, em comparação com $12,15 \%$ do sexo masculino. Já quanto à faixa etária destes, observou-se que $14,92 \%$ possuíam entre 20 e 25 anos, $81,77 \%$ encontravam-se com idades entre 25 e 35 anos, e $3,31 \%$, com idade superior a 35 anos.

A primeira questão do item I, sobre o processo de formação em fisioterapia, conforme apresentado na tabela 1 do presente artigo, tratava-se de caracterizar alguns itens relacionados com a graduação na Furb como pontos fortes, intermediários ou frágeis da graduação, considerando forte a pontuação $>8,0$; intermediário de 5,0 a 7,9; e frágil como $<5,0$.

Em relação às características 


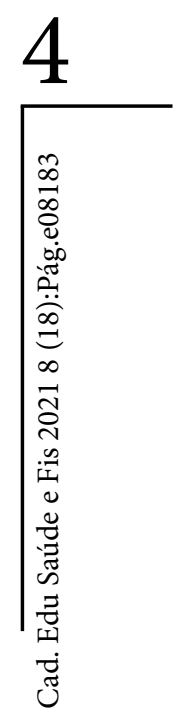

curriculares e distribuição das disciplinas ofertadas pelo curso, $53,59 \%$ dos egressos a consideraram como de nível intermediário; assim como as atividades e oportunidades de ensino e extensão também se enquadram no mesmo quesito, correspondendo a quase $45,86 \%$ dos questionários respondidos.

Como pontos fortes da graduação, destacaram-se as aulas práticas em laboratórios e ambientes externos $(56,91 \%)$, a experiência de estágio curricular $(72,38 \%)$ e a estrutura física da universidade e do curso $(71,27 \%)$.

Quando questionados sobre a carência de alguma disciplina, 55,20\% dos ex-alunos responderam que não sentiram falta. No entanto, $44,80 \%$ confirmaram que faltaram assuntos importantes durante a formação desses egressos, que, a partir de agora, podem ser revistos para se tornarem mais enfatizados.

Sobre a atuação profissional dos egressos, $68 \%$ deles trabalham somente com a fisioterapia hoje; $19 \%$ trabalham com a profissão associada a outra atividade; $11 \%$ trabalharam, porém não atuam mais hoje; e apenas $2 \%$ nunca atuaram na área.

Tabela 1- Pontos fortes, intermediários e frágeis da graduaçăo

\begin{tabular}{|c|c|c|c|}
\hline \multirow{2}{*}{ CARACTERISTICAS } & \multicolumn{3}{|c|}{ Intensidade } \\
\hline & Frágil & Intermediário & Forte \\
\hline $\begin{array}{l}\text { Caracteristica curricular e distribuiçăo das } \\
\text { disciplinas }\end{array}$ & $4(2,21 \%)$ & $97(53,59 \%)$ & $80(44,20 \%)$ \\
\hline $\begin{array}{l}\text { Aulas práticas em laboratórios e ambientes } \\
\text { externos }\end{array}$ & $7(3,87 \%)$ & $71(39,23 \%)$ & $103(56,91 \%)$ \\
\hline Experiéncia de estágio curricular & $6(3,31 \%)$ & $44(24,31 \%)$ & $131(72,38 \%)$ \\
\hline $\begin{array}{l}\text { Atividades e Oportunidades de ensino e } \\
\text { extensalo }\end{array}$ & $25(13,81 \%)$ & $83(45,86 \%)$ & $73(40,33 \%)$ \\
\hline $\begin{array}{l}\text { Estrutura fisica da universidade e do curso } \\
\text { de fisioterapia }\end{array}$ & $2(1,10 \%)$ & $50(27,62 \%)$ & $129(71,27 \%)$ \\
\hline
\end{tabular}


A respeito do tempo necessário para conseguir o primeiro emprego, conforme retratado na tabela 2 , ambos os estudos foram equivalentes e não tiveram diferenças significativas no Teste Qui-Quadrado, obtendo-se, consecutivamente, $82,76 \%$ e $72,38 \%$ dos egressos levando menos de oito semanas para encontrar um local e atuar. Ainda no estudo atual, aproximadamente $20 \%$ do restante demorou cerca de menos de seis meses para ser empregado, sugerindo a existência de oportunidades na região. Apesar de esse item ter se revelado positivo para a situação do recém-formado, a questão salarial foi considerada incompatível com o referencial de honorários fisioterapêuticos estabelecidos pelo Conselho Regional de Fisioterapia e Terapia Ocupacional (Crefito) por mais de $64 \%$ dos entrevistados; assim como cerca de $64 \%$ dos egressos do estudo anterior de Struck e Bretzke relataram também não ter salários compatíveis com suas atividades no local de trabalho quando recém-formados ${ }^{7}$.

Em relação as áreas de atuação do primeiro emprego, foram mencionadas em maior proporção: ortopedia $(60 \%)$, neurologia (11\%) e cardiorrespiratória (9\%). As restantes opções somadas não ultrapassaram $20 \%$, estando incluídas em maior proporção ordenadamente: fisioterapia dermatofuncional, pediatria, desportiva, saúde coletiva e reumatologia. Ademais, outras atuações relatadas pelos egressos foram método pilates, terapias manuais, saúde do trabalhador e urologia e ginecologia.
Quando questionados sobre a preferência pela área que atuaram nesse primeiro emprego, aproximadamente $70 \%$ responderam que havia preferência pela área. Ademais, ao serem indagados sobre a segurança em atendimentos de rotina, revelou-se que $82,87 \%$ dos egressos afirmaram se sentir seguros.

Outro aspecto abordado foi relacionado com a situação atual do egresso. Quanto à área de atuação no presente momento, temos outra vez o aparecimento da base histórica da profissão, sugerindo ainda uma visão mais voltada ao processo reabilitativo, com destaque principal para ortopedia $(50 \%)$, seguida por cardiorrespiratória $(14,40 \%)$ e neurologia $(13,60 \%)$. No entanto, a maior parte (86\%) respondeu que atua na sua área de preferência, e $90,06 \%$ dos egressos reconheceram-se satisfeitos profissionalmente.

Ao serem questionados sobre o local de atuação, ambos os estudos revelaram em sua maioria três ambientes: clínicas em 35,96\% das respostas, consultórios em cerca de $30,34 \%$, e hospitais em aproximadamente $12 \%$. Os outros locais citados foram prefeituras $(4,49 \%)$, organizações $(10,67 \%)$ e home care $(6,74 \%)$. Já em sua minoria, na opção "outros", foram apontados os escritórios, as instituições de ensino e os estúdios, além da Associação de Pais e Amigos dos Excepcionais (Apae) e Organizações Não Governamentais (ONG), o que sugere a ampliação do campo de trabalho do fisioterapeuta ainda em ascensão.

Tabela 2 - Tempo que levou para conseguir o $1^{\circ}$ emprego

\begin{tabular}{|c|c|c|c|}
\hline \multirow{2}{*}{ CARACTERISTICA } & \multicolumn{2}{|c|}{$\begin{array}{l}\text { Periodo } \\
\end{array}$} & \multirow{2}{*}{$\mathbf{P}$} \\
\hline & $2008(\mathrm{n}=87)$ & $2017(\mathrm{n}=181)$ & \\
\hline $\begin{array}{l}\text { Número de egressos que kvou menos } \\
\text { de } 8 \text { semanas para conseguir o } 1^{\circ} \\
\text { emprego }\end{array}$ & $72(82,76 \%)$ & $131(72,38 \%)$ & 0,06333 \\
\hline
\end{tabular}

Valor de $\mathrm{P}$ do teste de proporçōes independentes. Se $\mathrm{P}<0,05$ então existem diferenças significatinas. 
Já quando questionados sobre a ligação existente com seu local de trabalho, conforme retratado na tabela 3 , assim como na pesquisa de Struck e Bretzke, os resultados se aproximaram no quesito funcionário, em que, em ambos, mais de $30 \%$ dos egressos entraram nesta categoria ${ }^{7}$. No estudo atual, entretanto, foi incluída a opção "Autônomo", que obteve também resultado expressivo com $26,40 \%$ dos egressos.

Tabela 3 - Ligação com o local de trabalho

\begin{tabular}{l|cc}
\hline CARACTERÍSTICA & Frequência & $\%$ \\
\hline Funcionário & 64 & 35,96 \\
Prestador de serviço & 12 & 6,74 \\
Autônomo & 47 & 26,40 \\
Proprietário & 35 & 19,66 \\
Sócio & 20 & 11,24 \\
\hline Total & $\mathbf{1 7 8}$ & $\mathbf{1 0 0 , 0 0}$ \\
\hline
\end{tabular}

Sobre a faixa salarial atual dos egressos, apesar de haver um Referencial Nacional de Honorários Fisioterapêuticos mínimo ao invés de um piso salarial, obtiveram-se, no estudo atual $62,98 \%$, dos egressos recebendo entre 3 e 5 salários mínimos mensalmente.

As pesquisadoras incluíram um questionamento no qual os egressos deveriam responder se optariam novamente pelo curso escolhido se voltassem ao vestibular, obtendo resultado foi surpreendentemente gratificante, observando que $71,30 \%$ responderam "sim".
A última categoria do presente estudo foi voltada para as questões de especialização e futuro profissional do egresso, ou seja, a continuidade dos estudos. Quando interrogados sobre a realização de alguma especialização profissional na área de fisioterapia, obteve-se a resposta “sim" para 61,68\% dos questionários.

Quanto aos egressos que afirmaram ter realizado uma especialização, as formações mais buscadas nos métodos e áreas mencionadas foram: acupuntura; método Bobath; Busquet; cardiorrespiratória; dermatofuncional desportiva; ergonomia; neurofuncional; ortopedia e traumatologia; osteopatia; pediatria; neonatologia; 
pilates; terapia intensiva e uroginecologia.

Concluindo o estudo, a respeito dos planos para o futuro profissional, $83,10 \%$ dos egressos optaram pela resposta "sim", revelando o interesse em buscar formações continuadas, por meio de projetos como pós-graduação, mestrado e doutorado, além da pretensão em seguir carreira como docente e, também, de tornarem-se empreendedores, almejando gerenciar e viver do seu próprio negócio.

\section{DISCUSSÃO}

Como grupo principal da pesquisa, encontram-se o sexo feminino e a faixa etária de 25 a 35 anos, representando, assim, egressos jovens. Esse grupo de indivíduos está cada vez mais consciente da situação econômica e empregatícia no País, iniciando sua jornada profissional consideravelmente mais cedo, buscando conhecimento especializado o quanto antes para se preparar para o mercado de trabalho, que exige profissionais qualificados, competitivos e eficientes8. Já com relação ao aspecto da feminização encontrado entre esses profissionais, o resultado é compatível com a literatura, que revelou ser do sexo feminino a maior tendência dos profissionais da área da saúde, inclusive sendo esse fenômeno constatado ainda no período da graduação.

Quando questionados sobre itens relacionados com a graduação na Furb, em relação às características curriculares e distribuição das disciplinas, a maioria dos estudantes as consideraram de nível intermediário, assim como as atividades e oportunidades de ensino e extensão. Tais atividades são de interesse do estudante, e podem colaborar proporcionando participação do discente em situações reais de vida e trabalho e, consequentemente, contribuir fundamentalmente no processo de formação humana e profissional ${ }^{9}$.

Como pontos fortes da graduação, destacaram-se as aulas práticas em laboratórios e ambientes externos, a experiência de estágio curricular e a estrutura física da universidade e do curso. Esses pontos já haviam sido classificados da mesma maneira no estudo de Struck e Bretzke em 2008. Os principais diferenciais que os cursos devem ter são a interdisciplinaridade e o grande percentual de aulas desse gênero, o que pode refletir na interação entre as especialidades oferecidas em um local, permitindo, assim, que o paciente seja visto de forma holística e atendido de maneira humanizada ${ }^{10}$.

No presente estudo, poucos itens relacionados com o processo de formação foram classificados como frágil perante a visão dos egressos, destacando-se, nesse caso, em maior proporção, as "Atividades e oportunidades de ensino e extensão". Entretanto, na pesquisa anterior, os ex-alunos destacaram como pontos frágeis quesitos que agora já são mencionados positivamente, como, por exemplo, as aulas práticas. Tal resposta pode sugerir então que mudanças para melhor ocorreram dentro da organização do curso no decorrer desses nove anos para não terem sido mencionadas novamente.

Partindo para a próxima categoria da pesquisa, quando questionados sobre a atuação profissional dos egressos, $68 \%$ deles relataram que trabalham somente com a fisioterapia; tais resultados vão ao encontro do que Struck e Bretzke observaram, quando também $68,97 \%$ dos seus participantes relataram trabalhar somente com a fisioterapia ${ }^{7}$. Tal resultado pode sugerir que a maior parte dos acadêmicos formados consegue viver exclusivamente da profissão.

Quanto ao tempo necessário para conseguir o primeiro emprego, ambos os estudos foram equivalentes. Nas últimas décadas, houve crescimento da fisioterapia no País, ampliando o número de vagas ofertadas e, consequentemente, o número de profissionais empregados no mercado ${ }^{11}$.

Apesar de esse item ter se revelado positivo para a situação do recém-formado, os salários e as funções naquele momento não foram considerados compatíveis de acordo com o referencial de honorários fisioterapêuticos estabelecidos pelo 
Conselho Federal de Fisioterapia e Terapia Ocupacional (Coffito). Torna-se então importante enfatizar a grande necessidade da formação de um piso salarial pelo Coffito para a classe profissional, para que o investimento realizado na formação valha a pena e corresponda ao retorno financeiro almejado pelos profissionais fisioterapeutas, sem que haja exploração.

Quando abordados sobre a área de atuação, percebe-se uma prevalência das áreas de ortopedia, neurologia e cardiorrespiratória, seguidas de pediatria, reumatologia, desportiva e dermatofuncional, o que sugere a existência de uma forte tendência dos egressos de fisioterapia da Furb para atuações relacionadas com a reabilitação - lembrando que a maioria dos egressos relataram ter atuado em sua área de preferência no seu primeiro emprego.

Apesar de, em ambos os estudos, a maior parte dos egressos ter-se revelado segura para os atendimentos de rotina, as diferenças estatísticas significativas nos resultados do Teste Qui-Quadrado deixam claro que, no estudo atual, houve ainda maior aumento do número de respostas positivas. Tal dado pode ser devido ao fato de que o número de egressos participantes da pesquisa aumentou, assim como pode estar relacionado com uma grande parcela de estes estar atualmente se sentindo realmente mais apta e segura para realizar suas atividades agora do que há nove anos.

A categoria III da pesquisa abordou aspectos relacionados com a situação atual do egresso, sendo que as áreas de atuação seguiram um padrão e novamente temos representadas as áreas de base histórica da profissão (ortopedia, cardiorrespiratória e neurologia). Porém, a fisioterapia dermatofuncional, desportiva, saúde coletiva e pediatria foram, respectivamente, as outras áreas citadas em maior proporção, o que pode sugerir um processo de evolução, em que os fisioterapeutas estão atuando cada vez de forma mais generalista.

O questionamento acerca da satisfação profissional vai ao encontro do estudo de Struck e Bretzke ${ }^{7}$, em que em ambos os egressos relataram sentir-se satisfeitos com a profissão atual. Acerca desse item, podemos refletir que a sensação de satisfação pode estar refletida no fato de termos egressos que concluíram um curso pelo qual sentiam aptidão, por trabalharem na sua área de preferência, terem reconhecimento perante os outros, ou até mesmo pelo salário recebido.

Como visto nos resultados, a maior atuação dos egressos é em clínicas, seguida de consultórios e, posteriormente, em hospitais, Organizações, home care e prefeitura. Em consequência das habilidades e competências adquiridas na graduação e em cursos de pós-graduação, o fisioterapeuta hoje está atuando nos mais diferentes locais ${ }^{12}$.

Sobre a faixa salarial atual dos egressos, apesar de haver um Referencial Nacional de Honorários Fisioterapêuticos mínimo ao invés de um piso salarial, obtiveram-se, no estudo atual, $62,98 \%$ dos egressos recebendo entre 2 e 5 salários mínimos mensalmente; mostrando, a partir do Teste Qui-Quadrado, diferenças significativas nas duas pesquisas, sendo que atualmente há um maior número de egressos fisioterapeutas recebendo nessa faixa salarial. Tal fator o pode ser baseado no aumento de número de egressos sujeitos da pesquisa, como também na melhora da questão salarial em relação ao ano de 2008. A partir da questão salarial, foram questionados sobre a possibilidade de optarem novamente pelo curso escolhido caso voltassem ao vestibular, obtendo-se assim um retorno positivo, em que $71,30 \%$ responderam "sim".

A última categoria do presente estudo foi voltada para as questões de especialização e futuro profissional do egresso. Quando interrogados sobre a realização de alguma especialização profissional na área de fisioterapia, obteve-se uma porcentagem inferior ao compararmos com o estudo anterior de Struck e Bretzke.

Dos egressos que afirmaram ter realizado uma especialização, as formações mais buscadas nos métodos e áreas mencionadas foram: acupuntura, método Bobath, Busquet, cardiorrespiratória, entre outras. Uma boa formação acadêmica facilita o processo de inserção no mercado de trabalho, mas, ainda assim, há necessidade, por parte desses profissionais, de estarem constantemente seguindo os estudos e se aperfeiçoando por causa da grande concorrência no mercado de trabalho ${ }^{13}$. 
O número de egressos que buscam por especializações pode se justificar, além do mais, no interesse em aumentar sua renda mensal, em expandir o número de clientes/pacientes, em enriquecer seu currículo, em ter maiores chances de obter cargos e funções, entre outros.

\section{CONCLUSÕES}

O estudo em questão possibilitou a análise do perfil profissional dos egressos do Curso de Fisioterapia da Furb, tendo como resultado um alcance satisfatório de dados, podendo, assim, identificar os pontos fortes e fracos na área do ensino disponibilizado pela graduação, além do nível de satisfação do egresso com a sua formação, profissão e trajetória profissional.

Ao serem questionados sobre os aspectos de formação universitária, obteve-se um alto índice de respostas favoráveis quanto à estrutura da universidade, aulas práticas e experiência de estágio curricular proporcionadas pelo curso, o que é de grande relevância para o departamento, pois, em comparação com o estudo anterior, sugere-se melhora na qualidade e nos métodos de ensino, que não haviam sido relatados como positivos anteriormente.

Quanto ao perfil profissional dos egressos, encontramos, em sua maioria, profissionais nas áreas de ortopedia, neurologia e cardiorrespiratória. Em ambos os estudos, tais se apresentaram comprometidos com o conhecimento, com o objetivo de proporcionar benefícios diferenciados aos seus pacientes e clientes.

A parcela significativa de egressos empregados em um período menor que oito semanas e de egressos com nível de satisfação profissional elevado deixa claro ainda que, apesar de existirem contrapontos como a faixa salarial mensal baixa, há cada vez mais reconhecimento e oportunidades para a profissão na região.
Com a construção deste estudo, alcançou-se o objetivo de proporcionar subsídio científico para o colegiado em suas diretrizes, quanto ao currículo e metodologia, para que, consequentemente, pudesse haver melhora na formação dos fisioterapeutas concluintes da Furb, tornando-os crescentemente mais qualificados para uma atuação generalista.

Entre as sugestões deixadas para os próximos trabalhos, encontram-se a realização da pesquisa com instrumento qualitativo, para egressos específicos das três áreas de maior atuação (ortopedia, neurologia e cardiorrespiratória), e a realização da pesquisa de forma adaptada e ampla, para todos os egressos do Centro de Ciências da Saúde (CCS) da Furb.

\section{REFERÊNCIAS}

1. Badaró AFV, Guilhem D. Perfil sociodemográfico e profissional de fisioterapeutas e origem das suas concepções sobre ética. Rev Fisioter Mov. 2011;24(3):445-54.

2. Akerman M, Luiz OC. Avaliação da atenção primária: uma breve aproximação de conceitos e caminhos. Brasília: Conass; 2004.

3. Sobrinho JD. Avaliação e transformações da educação superior brasileira (19952009): do Provão ao SINAES. Avaliação (Campinas). 2010;15(1):195-224.

4. Ribeiro JLLS. Avaliação das universidades brasileiras as possibilidades de avaliar e as dificuldades de ser avaliado. Avaliação (Campinas). 2011;16(1):57-71.

5. Lousada ACZ, Martins GA. Egressos como fonte de informação à gestão dos cursos de Ciências Contábeis. Rev Contab Fin. 2005;16(37):73-84.

6. Gil AC. Como elaborar projetos de pesquisa. 4. ed. São Paulo: Atlas; 2002.

7. Struck A, Bretzke L. Análise do perfil profissional dos egressos dos egressos do curso de fisioterapia da Universidade Regional de Blumenau 
[monografia].- Blumenau (SC): Universidade Regional de Blumenau; 2008.

8. Fonseca MA. Graduação em fisioterapia: um estudo no ciclo de formação básica rumo a melhoria da qualidade de ensino professional [dissertação].- Florianópolis (SC): Universidade Federal de Santa Catarina; 2002.

9. Teixeira LJ, Oliveira MAC. Estágios curriculares em fisioterapia. Fisioter Bras. 2007;8(1):57-63.

10. Fernandes JGD, Gico VV. Clínicas Integradas da Faculdade Natalense para o Desenvolvimento do Rio Grande do Norte - FARN. Revista da FARN. 2008;7(2):163-9.

11. Marques AP. Para onde caminha a fisioterapia? Fisioter Pesq. 2002;9(1):i.

12. Barros FBM. A formação do fisioterapeuta na UFRJ e a profissionalização da fisioterapia [dissertação]. Rio de Janeiro (RJ): Universidade do Estado do Rio de Janeiro; 2002.

13. Martens CDP, Freitas H. Influência do ensino de empreendedorismo nas intenções de direcionamento profissional dos estudantes. Estudo \& Debate. 2008;15(2):71-95.

Recebido: 19/11/2019

Aprovado: 09/09/2021 